Check for updates

Cite this: Mater. Adv., 2022, 3, 2908

Received 15th November 2021 Accepted 6th February 2022

DOI: $10.1039 / \mathrm{d} 1 \mathrm{ma01076j}$

rsc.li/materials-advances

\section{Chemical order or disorder - a theoretical stability expose for expanding the compositional space of quaternary metal borides $\dagger$}

\begin{abstract}
Martin Dahlqvist (D) * and Johanna Rosen (D) *
Inspired by the recent discovery of $\mathrm{Ti}_{4} \mathrm{MoSiB}_{2}$, a quaternary phase with out-of-plane chemical order that we denote as $O-M A B$, we perform an extensive first-principles study to explore the attained chemical order and disorder (solid-solution) upon metal alloying of $M_{5} A B_{2}$ (T2 phases), with $M$ from Groups 3 to 9 and $\mathrm{A}=\mathrm{Al}, \mathrm{Si}, \mathrm{P}, \mathrm{Ga}$, and $\mathrm{Ge}$. We show that the attainable chemistries of $\mathrm{T} 2$ can be significantly expanded and predict 35 chemically ordered $0-M A B$ phases and 121 solid solutions of an $M_{4}^{\prime} M^{\prime \prime} A B_{2}$ stoichiometry. The possibility of realizing $0-M A B$ or solid solution MAB phases combined with multiple elemental combinations previously not observed in these borides suggests an increased property tuning potential. Furthermore, five ternary T2 phases, yet to be synthesized, are also predicted to be stable.
\end{abstract}

\section{Introduction}

The contemporary exploration of layered materials is propelled by their physical and chemical properties as well as their potential use as a precursor for conversion into 2D materials. MAX phases $(\mathrm{M}=$ transition metal, $\mathrm{A}=\mathrm{A}$-group element and $\mathrm{X}=\mathrm{C}$ and/or $\mathrm{N}$ ) are a family of atomically laminated hexagonal materials which combine the attributes of both metallics and ceramics, such as being machinable, excellent electrical and thermal conductivities, thermal shock and oxidation resistance. ${ }^{1-3}$ MAX phases are also the precursor materials for their two-dimensional (2D) derivatives, MXenes, realized from the selective etching of the A-element. ${ }^{4}$ MXenes have attracted huge interest due to their exceptional properties such as hydrophilicity, high electrical conductivity and volumetric capacitance, making them beneficial for numerous applications including energy storage and electromagnetic interference shielding. ${ }^{5-8}$ Recently, chemically ordered MAX phases ( $i$-MAX and $o$-MAX), i.e. quaternary compounds displaying inplane or out-of-plane chemical order for two M elements, ${ }^{9-11}$ have been converted into MXenes upon selective etching. ${ }^{10,12-15}$

So-called MAB phases are also atomically laminated, though they display different crystal structures and show a wider palette of structural variations, from orthorhombic $\mathrm{M}_{n+1} \mathrm{AlB}_{2 n}$ (with $n=1-3$ ), ${ }^{16-18} \mathrm{MAlB}^{17}$ and $\mathrm{M}_{4} \mathrm{AlB}_{4},{ }^{19}$ hexagonal $\mathrm{M}_{2} \mathrm{AB}_{2},{ }^{20,21}$ to tetragonal $\mathrm{M}_{5} \mathrm{AB}_{2}$ (T2), ${ }^{22}$ but with $\mathrm{M}$ mainly from Groups 6 to

Materials Design, Department of Physics, Chemistry and Biology (IFM), Linköping University, SE-58183 Linköping, Sweden. E-mail: martin.dahlqvist@liu.se, johanna.rosen@liu.se

$\dagger$ Electronic supplementary information (ESI) available. See DOI: 10.1039/d1ma01076j
9. There are a few reports on the attempted synthesis of $2 \mathrm{D}$ MBenes through selective etching of layered ternary MAB phases $;^{23-25}$ however, the realization of individual single-layer sheets from these materials still remains a quest.

In a recent study, we considered metal alloying as a path towards expanding the attainable chemistries in orthorhombic and hexagonal $\mathrm{M}_{2} \mathrm{AlB}_{2}$ and discovered two in-plane chemically ordered MAB phases, $\mathrm{Mo}_{4 / 3} \mathrm{Y}_{2 / 3} \mathrm{AlB}_{2}$ and $\mathrm{Mo}_{4 / 3} \mathrm{Sc}_{2 / 3} \mathrm{AlB}_{2}$, coined $i$ - $\mathrm{MAB}^{26}$ (analogous to $i$-MAX), ${ }^{10}$ along with an additional 13 $i$-MAB and 16 solid solution phases that were predicted to be stable. This exemplifies alloying as a prospective path to expand MAB phase chemistries which when combined with various MAB structures would allow for a range of possibilities when it comes to novel elemental combinations, bond modification, and property tuning. Bond modification in an MAB alloy could for example allow for conversion into its 2D derivative, MBene or boridene, in the same way as the conversion of $i$-MAX to $i$ MXene. ${ }^{27}$ Indeed, most recently the first $2 \mathrm{D}$ metal boride, named boridene, has been experimentally realized in the form of single sheets of $\mathrm{Mo}_{4 / 3} \mathrm{~B}_{2-x}$, selectively etched from the $i$-MABphases $\left(\mathrm{Mo}_{2 / 3} \mathrm{Sc}_{1 / 3}\right)_{2} \mathrm{AlB}_{2}$ and $\left(\mathrm{Mo}_{2 / 3} \mathrm{Y}_{1 / 3}\right)_{2} \mathrm{AlB}_{2} \cdot{ }^{28}$

Herein we consider the tetragonal and atomically layered $\mathrm{T} 2$ phases, which were discovered in 1957 when Nowotny et al. synthesized the prototypical $\mathrm{Mo}_{5} \mathrm{SiB}_{2}$, followed by the synthesis of $\mathrm{Fe}_{5} \mathrm{SiB}_{2}$ and $\mathrm{Mn}_{5} \mathrm{SiB}_{2}$ phases in $1960 .{ }^{22,29} \mathrm{~T} 2$ phases have an $\mathrm{M}_{5} \mathrm{AB}_{2}$ composition in an $14 / \mathrm{mcm}$ space group symmetry, where $M$ is a transition metal from Groups 5 to 9 , and $A$ is an $A$ element ( $\mathrm{Si}, \mathrm{Ge}$, and $\mathrm{P}$ ). $\mathrm{T} 2$ phases are attractive due to their high oxidation resistance, ${ }^{30}$ nearly isotropic thermal expansion, ${ }^{31}$ superconducting properties ${ }^{32,33}$ and potential for use as rare-earth free permanent magnets. ${ }^{34-36}$ 
We have recently shown that metal alloying in Si-based T2 phases holds potential for a range of new compositions, including the discovered out-of-plane ordered $\mathrm{Ti}_{4} \mathrm{MoSiB}_{2}$, called $o$-MAB. ${ }^{37}$ It has been demonstrated that the bonds between the two metallic sites, Ti and Mo, are key to the stability of this specific structure. ${ }^{38}$ In the present work we use a systematic theoretical approach to demonstrate the expansion of the possible chemistries for T2 phases, beyond $\mathrm{A}=\mathrm{Si}$, both with respect to ternary and quaternary compositions. The latter by exploiting metal alloying on the two crystallographic unique metal sites by considering both the chemically ordered (out-of-plane ordered $o$-MAB, $\mathbf{M}_{4}^{\prime} \mathrm{M}^{\prime \prime} \mathrm{AB}_{2}$ ) and disordered (solid solution, $\left.\left(\mathrm{M}_{0.8}^{\prime} \mathrm{M}_{0.2}^{\prime \prime}\right)_{5} \mathrm{AB}_{2}\right)$ distribution of $\mathbf{M}^{\prime}$ and $\mathbf{M}^{\prime \prime}$. Guided by thermodynamic stability calculations, we confirm the stability for experimentally known ternary and quaternary T2 phases. More importantly, we also predict 35 stable $o$-MAB phases and 121 stable solid solutions, which are yet to be experimentally discovered.

Furthermore, we investigate the impact of the choice of the element ( $\mathbf{M}^{\prime}$ and $\mathbf{M}^{\prime \prime}$, and $\left.\mathbf{A}\right)$ and the effect of the size and electronegativity of $\mathbf{M}^{\prime}$ and $\mathbf{M}^{\prime \prime}$ on the formation of chemically ordered $(o-\mathrm{MAB})$ or solid solution MAB phases. We also propose guidelines as which elemental combination needs to be employed in the experimental discovery of a stable phase with chemical order or disorder. This study reveals that alloying is a fruitful pathway for expanding the concept of T2 phases to include novel elemental combinations which, in turn, may provide tuneable and advantageous properties as well as the potential derivation of $2 \mathrm{D}$ materials from chemical exfoliation.

\section{Methods}

All first-principles calculations are performed by means of density functional theory (DFT) using the Vienna $a b$ initio simulation package (VASP) version 5.4.1..$^{39-41}$ The projector augmented wave method is used with the generalized gradient approximation (GGA) as parameterized by Perdew-BurkeErnzerhof (PBE). ${ }^{42-44}$ In systems with $\mathrm{Cr}, \mathrm{Mn}, \mathrm{Fe}, \mathrm{Co}$, and $\mathrm{Ni}$, we used the spin-polarized GGA version and energy is taken for the lowest ferromagnetic and antiferromagnetic configurations sampled within the unit cell. Further details of the considered magnetic spin configurations can be found in Fig. S1 (ESI $\dagger$ ). Note that while spin configurations with lower energy may exist, this approximation serves the purpose of indicating if the phase is stable or not. If found stable, a potential lower energy spin configuration will increase the stability even further.

For structural relaxation, the Brillouin zone was integrated with Monkhorst-Pack special $k$-point sampling, with a density of $0.05 \AA^{-1},{ }^{45}$ with a plane-wave energy cut-off of $400 \mathrm{eV}$. The convergence of formation enthalpy with respect to the $k$-point density and plane-wave energy cut-off, shown in Fig. S2 (ESI $\dagger$ ) for selected phases, demonstrates that the used settings ensure the $\Delta H_{\mathrm{cp}}$ values to be converged within less than $1 \mathrm{meV}$ per atom. The convergence criterion for self-consistency is reached when satisfying an energy convergence of $10^{-6} \mathrm{eV}$ per atom and a force convergence of $10^{-2} \mathrm{eV} \AA^{-1}$.

The $\mathrm{T} 2$ structure has a tetragonal $14 / \mathrm{mcm}$ space group symmetry in an $\mathrm{M}_{5} \mathrm{AB}_{2}$ composition, where $\mathrm{M}$ is a transition metal and $\mathrm{A}$ is an A-group element. In this work we have considered $\mathrm{M}$ from Groups 3 to 9; Sc, Y, Ti, Zr, Hf, V, Nb, Ta, $\mathrm{Cr}, \mathrm{Mo}, \mathrm{W}, \mathrm{Mn}, \mathrm{Fe}, \mathrm{Co}$, and Ni, along with traditional and nontraditional A elements; Al, Ga, Ge, Si, Ge, Sn, and P. Solid solutions, or chemical disorder, of $\mathbf{M}^{\prime}$ and $\mathbf{M}^{\prime \prime}$ are modelled on the $M$ sublattices, $16 \mathrm{l}$ and $4 \mathrm{c}$, simultaneously, using the special quasi-random structure (SQS) method. ${ }^{46}$ The convergence tests in Fig. S3 (ESI $\dagger$ ) show that the supercells with 160 or more atoms give a qualitatively accurate representation and a quantitative convergency in terms of calculated formation enthalpies, equilibrium volumes, and lattice parameters needed for the herein presented high-throughput study.

In general, the formation energy for a phase is given by,

$$
\Delta E_{\mathrm{f}}=E-\sum \mu_{i} x_{i}
$$

where $E$ is the calculated total energy of the phase, $\mu_{i}$ is the chemical potential of element $i$, and $x_{i}$ is the quantity of element $i$ in the phase. The standard convention is to consider the chemical potential of each species as the total energy of the elemental ground state crystal structure. With this choice, $\Delta E_{\mathrm{f}}$ is valid only for $0 \mathrm{~K}$. However, $\Delta E_{\mathrm{f}}$ is not an appropriate indicator for stability as demonstrated in Fig. S4 (ESI $\dagger$ ).

An alternative and a more comprehensive approach for assessing the thermodynamic stability of a phase is to compare its energy relative to competing phases in the ternary or quaternary system of interest. This will give information on whether the phase is energetically favored or prefer decomposition into other competing phases. The set of most competing phases, denoted as equilibrium simplex, is identified using a linear optimization procedure which has been proven successful to confirm the stability of already synthesized materials as well as to predict the existence of new ones. ${ }^{47-53}$ The stability of a phase is quantified in terms of the formation enthalpy $\Delta H_{\mathrm{cp}}$ by comparing its energy to the energy of the equilibrium simplex according to

$$
\Delta H_{\mathrm{cp}}=E\left[\left(\mathrm{M}_{1-x}^{\prime} \mathrm{M}_{x}^{\prime \prime}\right)_{5} \mathrm{AB}_{2}\right]-E[\text { equilibrium simplex }] .
$$

A phase is concluded stable when $\Delta H_{\mathrm{cp}}<0$. In the formula, $E\left[\left(\mathrm{M}_{1-x}^{\prime} \mathrm{M}_{x}^{\prime \prime}\right)_{5} \mathrm{AB}_{2}\right]$ represents the $\mathrm{M}$ element configuration (ordered/disordered) of the lowest energy. In this work we use the notation $\mathrm{M}_{4}^{\prime} \mathbf{M}^{\prime \prime} \mathrm{AB}_{2}$ for chemical order and $\left(\mathrm{M}_{1-x}^{\prime} \mathrm{M}_{x}^{\prime \prime}\right)_{5} \mathrm{AB}_{2}$ for a solid solution. In addition, when $T \neq 0 \mathrm{~K}$, the contribution from configurational entropy for a disordered distribution of $\mathbf{M}^{\prime}$ and $\mathbf{M}^{\prime \prime}$ on the $M$ sublattice in $\left(\mathbf{M}_{1-x}^{\prime} \mathbf{M}_{x}^{\prime \prime}\right)_{5} \mathrm{AB}_{2}$ will decrease the Gibbs free energy $\Delta G_{\mathrm{cp}}^{\text {disorder }}$ as approximated by

$$
\Delta G_{\mathrm{cp}}^{\text {disorder }}[T]=\Delta H_{\mathrm{cp}}^{\text {disorder }}-T \Delta S,
$$

where the entropic contribution $\Delta S$, assuming an ideal solution of $\mathbf{M}^{\prime}$ and $\mathbf{M}^{\prime \prime}$ on the $\mathbf{M}$-sites, is given by

$$
\Delta S=-2 k_{\mathrm{B}}[y \ln (y)+(1-y) \ln (1-y)],
$$


where $k_{\mathrm{B}}$ is the Boltzmann constant and $y$ is the concentration of $\mathbf{M}^{\prime \prime}$ on the $\mathbf{M}$-sublattices. Additional temperature effects, such as lattice vibrations, were not considered because this contribution from a phase, significant or not for an individual phase, tends to be cancelled out in the calculated stability. ${ }^{54}$

Visualization of atomic structures was done using the VESTA code. $^{55}$

\section{Results and discussion}

\section{Stability of ternary $\mathrm{T} 2$ phases}

Assessment of the thermodynamic stability for the ternary $\mathrm{T} 2$ phases with the $\mathrm{M}_{5} \mathrm{AB}_{2}$ composition, where $\mathrm{M}=\mathrm{Sc}, \mathrm{Y}, \mathrm{Ti}, \mathrm{Zr}, \mathrm{Hf}$, $\mathrm{V}, \mathrm{Nb}$, Ta, Cr, Mo, W, Mn, Fe, and Co; A = Al, Ga, In, Si, Ge, Sn, and $\mathrm{P}$, is presented in Fig. 1, showing the calculated formation enthalpy $\Delta H_{\mathrm{cp}}$ at $0 \mathrm{~K}$, where the blue regions represent stable phases $\left(\Delta H_{\mathrm{cp}}<\right.$ $0)$. The corresponding identified equilibrium simplex for each phase is listed in Table S1 (ESI $\dagger$ ). Thermodynamically stable, or close to stable, $\mathrm{M}_{5} \mathrm{AB}_{2}$ phases are found for $\mathrm{A}=\mathrm{Si}, \mathrm{P}$, and $\mathrm{Ge}$ combined with $M$ from Groups 5 to 9 while $M_{5} A_{2}$ phases with $M$ from Groups 3 and 4 or with $\mathrm{A}=\mathrm{In}$ and $\mathrm{Sn}$ are far from stable, evident from the red areas. Experimentally known $\mathrm{T} 2$ phases are marked by a black square (13 in total, see Table S2, ESI $\dagger$ ), and are here identified as stable or close to stable. The consistency between synthesized phases to date and the thermodynamic phase stability calculations supports our predictions of stable $\mathrm{T} 2$ phases, and five novel $\mathrm{T} 2$ phases, yet to be synthesized, are here predicted stable, i.e., $\mathrm{V}_{5} \mathrm{~PB}_{2}$, $\mathrm{Nb}_{5} \mathrm{~PB}_{2}, \mathrm{Ta}_{5} \mathrm{~PB}_{2}, \mathrm{~V}_{5} \mathrm{GeB}_{2}$, and $\mathrm{Nb}_{5} \mathrm{GeB}_{2}$. These phases remain to be verified, and synthesis experiments are encouraged.

\section{Stability upon metal alloying for quaternary T2 phases - order vs. disorder}

In a recent study we investigated the stability of $\mathrm{T} 2$ phases upon metal alloying for $\mathrm{M}_{5} \mathrm{SiB}_{2}$ and predicted 11 chemically ordered phases as well as 40 solid solutions to be stable, including the experimentally verified $\mathrm{Ti}_{4} \mathrm{MoSiB}_{2} \cdot{ }^{37}$ Here we expand the possible chemistries by also considering $\mathrm{A}=\mathrm{Al}, \mathrm{Ga}$, Ge and $\mathrm{P}$ upon metal alloying. We choose to not include $\mathrm{A}=\mathrm{In}$ and $\mathrm{Sn}$ in this study due to the rather large formation enthalpy $\Delta H_{\mathrm{cp}}$ shown for $\mathbf{M}_{5} \operatorname{InB}_{2}$ and $\mathbf{M}_{5} \mathrm{SnB}_{2}$ in Fig. 1 . We considered an $\mathbf{M}^{\prime}$ to $\mathbf{M}^{\prime \prime}$ ratio of $4: 1$ motivated by the two symmetrically independent $\mathbf{M}$ sublattices at Wyckoff sites $16 \mathrm{l}$ and 4c (Fig. 1h). We have considered two different distributions of $\mathbf{M}^{\prime}$ and $\mathbf{M}^{\prime \prime}$; (i) chemical order, denoted $o-\mathrm{MAB}$, with $\mathbf{M}^{\prime}$ and $\mathbf{M}^{\prime \prime}$ occupying the $16 l$ and $4 c$ M-sites, respectively, and (ii) solid solution, obtained by mixing $\mathbf{M}^{\prime}$ and $\mathbf{M}^{\prime \prime}$ on both sites simultaneously in an SQS generated supercell consisting of 160 atoms. Fig. 2 depicts a schematic illustration of $\mathbf{M}^{\prime}$ and $\mathbf{M}^{\prime \prime}$ distributed with chemical order, $o$-MAB, and disorder, in a solid solution.

Fig. 3 shows the trends in thermodynamic stability for 910 unique compositions. For each A element (A = Al, Si, P, Ga, Ge), a heatmap is shown, where $\mathbf{M}^{\prime}$ and $\mathbf{M}^{\prime \prime}$ are clustered according to the periodic group of $\mathrm{M}$ elements. The background color represents the calculated thermodynamic stability for chemical order/disorder of the lowest energy, with the blue region representing stable phases $\left(\Delta H_{o \text {-MAB }}\right.$ or $\left.\Delta G_{\text {solid solution }}<0\right)$. For the solid solution $\left(\mathrm{M}_{0.8}^{\prime} \mathrm{M}_{0.2}^{\prime \prime}\right)_{5} \mathrm{AB}_{2}$ we evaluate $\Delta G_{\text {solid solution }}$ at $2000 \mathrm{~K}$, motivated by a typical temperature of 1000 to $1900{ }^{\circ} \mathrm{C}$ (1273 to $2173 \mathrm{~K}$ ) used for the synthesis of $\mathrm{M}_{5} \mathrm{AB}_{2}$ (e.g. $\mathrm{M}=\mathrm{Mo}$, $\mathrm{W}, \mathrm{Mn})$ and $\left(\mathrm{Fe}_{0.8} \mathrm{M}_{0.2}^{\prime \prime}\right)_{5} \mathrm{AB}_{2}\left(\mathrm{M}^{\prime \prime}=\mathrm{Mn}, \mathrm{Co}\right),{ }^{35,36,56,57}$ by including the contribution of configurational entropy to Gibb's free energy, using eqn (3) and (4). The depicted symbol thus represents the chemical order of the lowest energy at $2000 \mathrm{~K}$; filled squares for ordered $\mathrm{M}_{4}^{\prime} \mathrm{M}^{\prime \prime} \mathrm{AB}_{2} O$-MAB and open circles for the solid solution $\left(\mathrm{M}_{0.8}^{\prime} \mathrm{M}_{0.2}^{\prime \prime}\right)_{5} \mathrm{AB}_{2}$. In addition, the experimentally reported $\mathrm{Ti}_{4} \mathrm{MoSiB}_{2} \quad o-\mathrm{MAB}$ and solid solution $\left(\mathrm{M}_{0.8}^{\prime} \mathrm{M}_{0.2}^{\prime \prime}\right)_{5} \mathrm{AB}_{2}$ are marked by pink and green squares, respectively. The result obtained at $0 \mathrm{~K}$, i.e., without a contribution
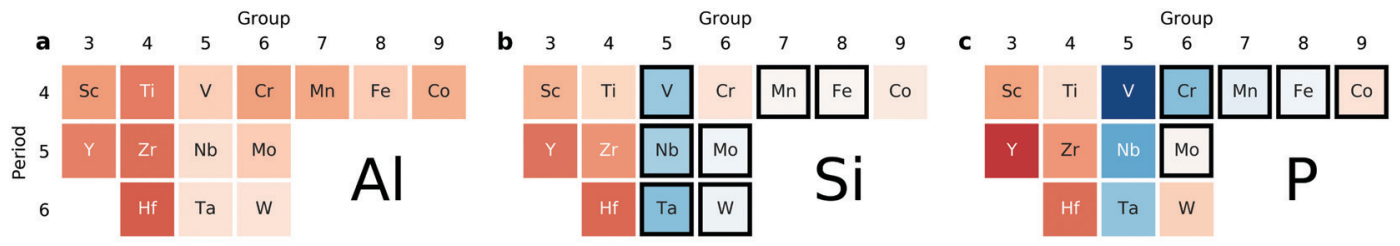

d

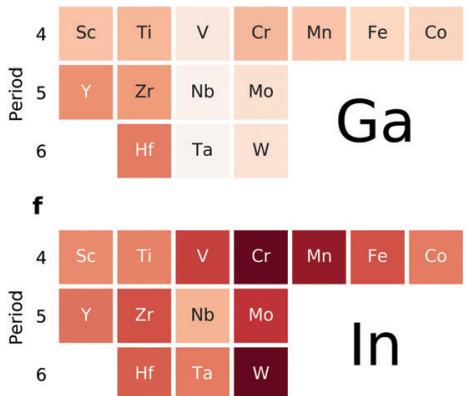

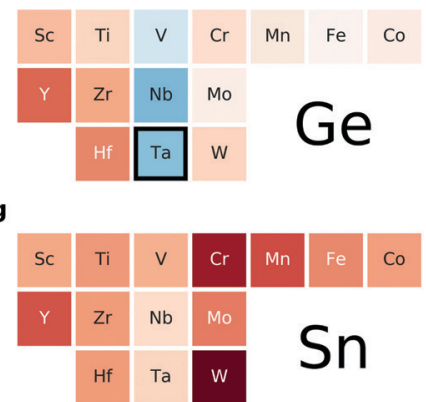
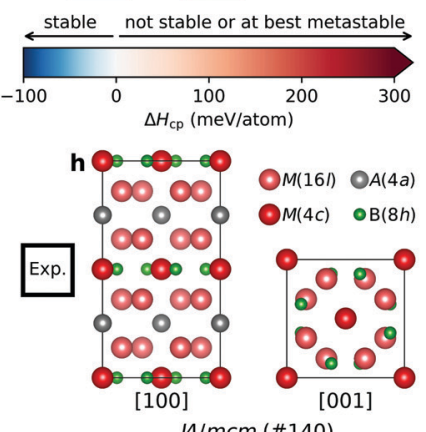

Fig. 1 (a-g) Calculated formation enthalpy $\Delta H_{c p}$ of $M_{5} A B_{2}$, known as $T 2$, with experimentally reported phases marked by a black square, for various $M$ and A elements. (h) Schematic illustration of a T2 phase along the [100] and [001] zone axes with $M, A$, and B represented by red, grey, and green atoms, respectively. 


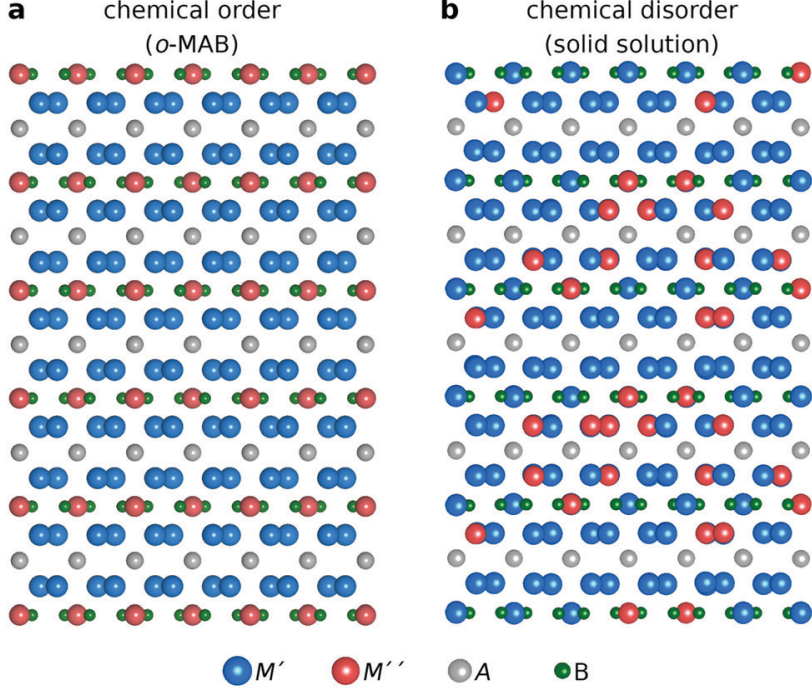

Fig. 2 Schematic illustration of a T2 phase upon metal alloying with $M^{\prime}$ and $M^{\prime \prime}$ distributed (a) ordered in an $O-M A B$ phase $M_{4}^{\prime} M^{\prime \prime} A B_{2}$ and (b) disordered in a solid solution $\left(\mathrm{M}_{0.8}^{\prime} \mathrm{M}_{0.2}^{\prime \prime}\right)_{5} A B_{2}$. The schematic is shown along the [100] zone axis with $\mathrm{M}^{\prime}, \mathrm{M}^{\prime \prime}, \mathrm{A}$, and $\mathrm{B}$ represented by blue, red, grey, and green atoms, respectively.

from the configurational entropy to the solid solution phases, is shown in Fig. S5 (ESI $\dagger$ ). The discrepancy between Fig. 3 and Fig. S5 (ESI $\dagger)$ highlights the importance of including the evaluation of entropy in the analysis, for reliable predictions.
All five experimentally reported solid solutions $\left(\mathrm{M}_{0.8}^{\prime} \mathrm{M}_{0.2}^{\prime \prime}\right)_{5} \mathrm{AB}_{2}$ are predicted to be stable here, ${ }^{35,36,56}$ as well as the recently discovered $\mathrm{Ti}_{4} \mathrm{MoSiB}_{2} o$-MAB. ${ }^{37}$ Noteworthily, the additional 121 solid solution and $35 o$-MAB phases are predicted to be stable, mainly for $\mathrm{A}=\mathrm{Si}, \mathrm{P}$, and $\mathrm{Ge}$, suggesting that metal alloying in $\mathrm{T} 2$ phases is a prospective path towards expanding the possible chemistries which, in turn, provide a high tunning potential of these materials. Table 1 summarizes the stable $o$-MAB and solid solution $\mathrm{MAB}$ phase compositions. The results highlight the value of computational material discoveries for accelerating exploratory synthesis in new chemical spaces. A complete list of predicted stable $o$-MAB and solid solution phases, with their calculated formation enthalpies and Gibbs free energies of formation, respectively, is given in Tables S5 and S6 (ESI $\dagger$ ). Examples of phases with predicted outstanding stability, strongly motivating attempted experimental verification, are $o$-MAB phases $\mathrm{Ti}_{4} \mathrm{M}^{\prime \prime} \mathrm{PB}_{2}\left(\mathrm{M}^{\prime \prime}=\mathrm{Cr}\right.$, Mo or $\left.\mathrm{Mn}\right)$, $\mathrm{Ta}_{4} \mathrm{M}^{\prime \prime} \mathrm{AB}_{2}\left(\mathrm{M}^{\prime \prime}=\mathrm{V}\right.$ or $\left.\mathrm{Cr} ; \mathrm{A}=\mathrm{Si}, \mathrm{P}, \mathrm{Ge}\right)$, and $\mathrm{Mo}_{4} \mathrm{M}^{\prime \prime} \mathrm{AB}_{2}\left(\mathrm{M}^{\prime \prime}=\mathrm{V}\right.$ or $\mathrm{Cr}$; $\mathrm{A}=\mathrm{Si}, \mathrm{P}, \mathrm{Ge})$ and solid solution MAB phases $\left(\mathrm{M}_{0.8}^{\prime} \mathrm{M}_{0.2}^{\prime \prime}\right)_{5} \mathrm{AB}_{2}\left(\mathrm{M}^{\prime}=\mathrm{V}\right.$, $\mathrm{Nb}$, Ta; $\mathrm{A}=\mathrm{Si}, \mathrm{P}, \mathrm{Ge})$ and $\left(\mathrm{M}_{0.8}^{\prime} \mathrm{W}_{0.2}\right)_{5} \mathrm{AB}_{2}\left(\mathrm{M}^{\prime}=\mathrm{V}, \mathrm{Nb}, \mathrm{Ta} ; \mathrm{A}=\mathrm{Si}, \mathrm{Ge}\right)$. Detailed structural data for $o-\mathrm{MAB}$ phases that are predicted to be stable can be found in Table S7 (ESI $\dagger$ ) and we encourage further exploration of various properties to find out new application possibilities for this family of materials.

\section{Order or disorder - impact on the size and electronegativity}

In ref. 38 , the bonding characteristics of the experimentally known $\mathrm{Ti}_{4} \mathrm{MoSiB}_{2} \quad o$-MAB phases were investigated and

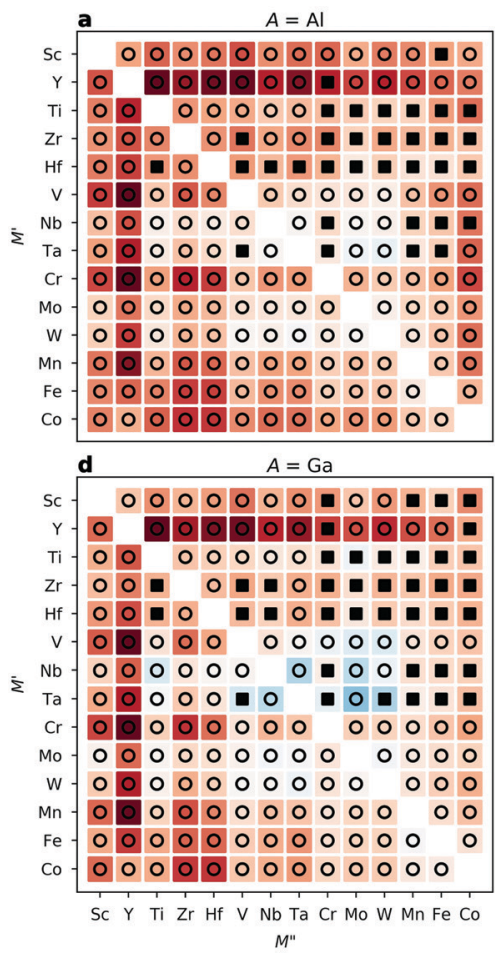

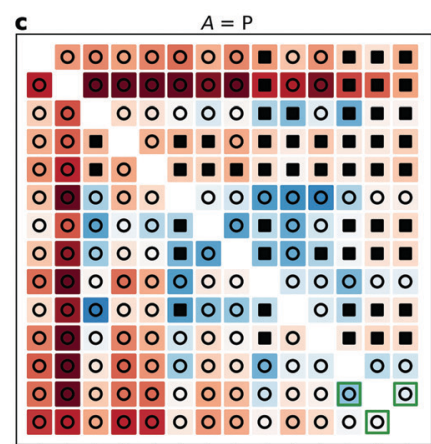

Sc Y Ti Zr Hf $\vee$ Nb Ta Cr Mo W Mn Fe Co

$M "$

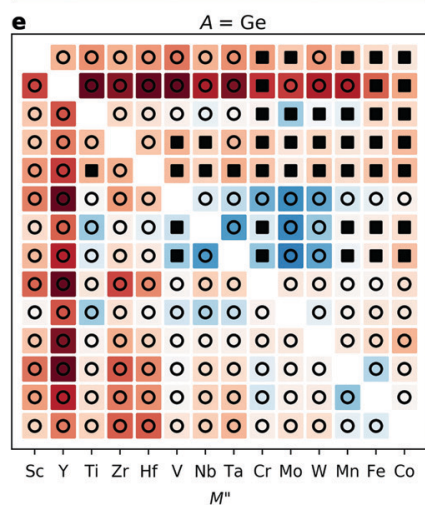

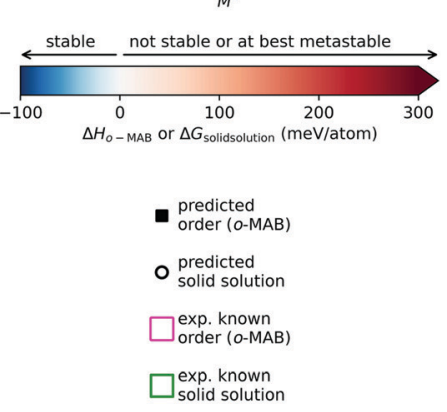

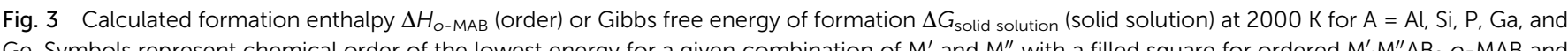
Ge. Symbols represent chemical order of the lowest energy for a given combination of $M^{\prime}$ and $M^{\prime \prime}$ with a filled square for ordered $M_{4}^{\prime} M M^{\prime \prime} A B_{2} O-M A B$ and
open circle for solid solution $\left(M_{0}^{\prime} M_{02}^{\prime \prime}\right)_{5} A B_{2}$. Experimentally known phases are marked with squares: chemically ordered $O-M A B$ in pink and disordered solid solution MAB phases in green. 
Table 1 Experimentally reported and theoretically predicted quaternary T2 phases, categorized by the calculated thermodynamic stability and their preference for ordered $\left(M_{4}^{\prime} M^{\prime \prime} A B_{2}\right)$ or disordered $\left(\left(M_{0.8}^{\prime} M_{0.2}^{\prime \prime}\right)_{5} A B_{2}\right)$ distribution of $M^{\prime}$ and $M^{\prime \prime}$ at a typical synthesis temperature of $2000 \mathrm{~K}$

Experimentally reported phases,

Phase Stability criteria

\begin{tabular}{ll}
\hline Stable $o$-MAB & $\Delta H_{o \text {-MAB }}<0$ \\
$\mathrm{M}_{4}^{\prime} \mathrm{M}^{\prime \prime} \mathrm{AB}_{2}$ & $\Delta G_{\text {solid solution }}>\Delta H_{o \text {-MAB }}$
\end{tabular}

Stable solid solution $\left(\mathrm{M}_{0.8}^{\prime} \mathrm{M}_{0.2}^{\prime \prime}\right)_{5} \mathrm{AB}_{2}$ also predicted stable

$\mathrm{Ti}_{4} \mathrm{MoSiB}_{2}{ }^{37}$

$\Delta G_{\text {solid solution }}<0$ $\Delta G_{\text {solid solution }}<\Delta H_{o-\mathrm{MAB}}$
$\left(\mathrm{Fe}_{0.8} \mathrm{Mn}_{0.2}\right)_{5} \mathrm{AB}_{2}(\mathrm{~A}=\mathrm{Si}, \mathrm{P})^{56}$

$\left(\mathrm{Fe}_{0.8} \mathrm{Co}_{0.2}\right)_{5} \mathrm{AB}_{2}(\mathrm{~A}=\mathrm{Si}, \mathrm{P})^{35,36,56}$
$\left(\mathrm{Co}_{0.8} \mathrm{Fe}_{0.2}\right)_{5} \mathrm{AB}_{2}(\mathrm{~A}=\mathrm{P})^{35}$
Phases predicted stable, not yet synthesized

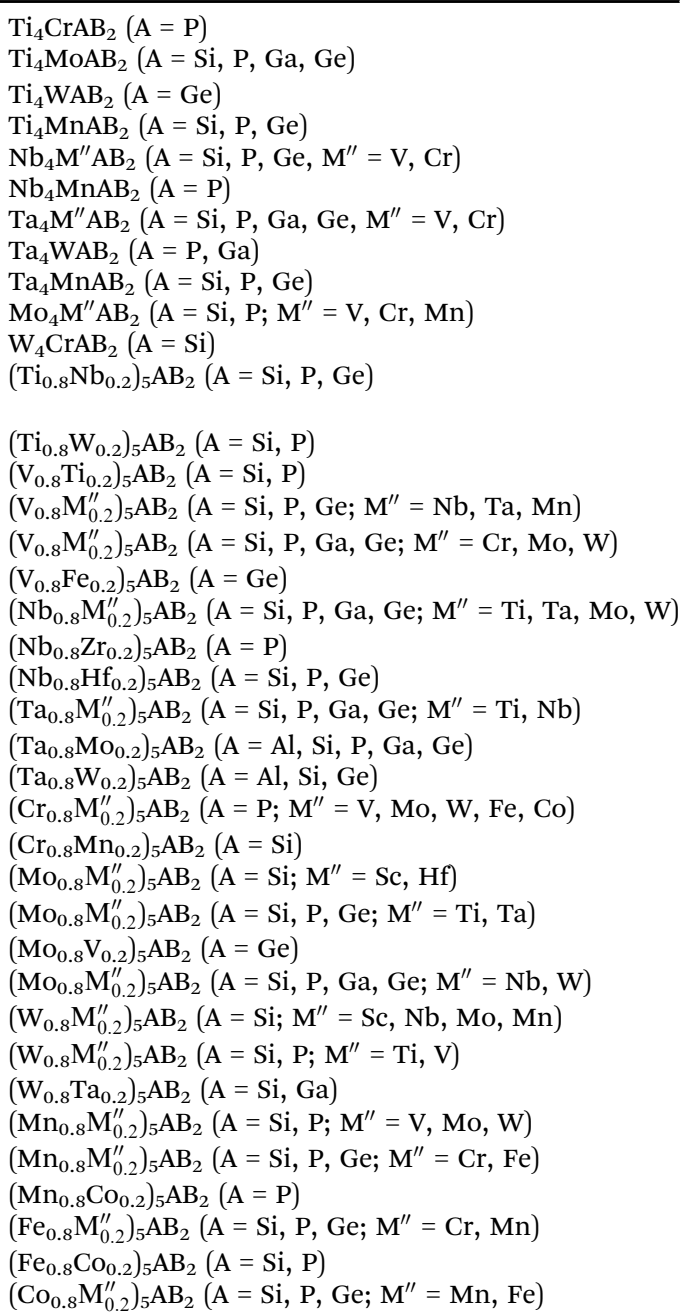

compared to those of the known $\mathrm{Mo}_{5} \mathrm{SiB}_{2}$ and the hypothetical $\mathrm{Ti}_{5} \mathrm{SiB}_{2}$. It was found that the bonding states are optimized in $\mathrm{Ti}_{4} \mathrm{MoSiB}_{2}$ and that the electronegativity difference of Mo and $\mathrm{Ti}$ could, at least in part, explain the stability of both $\mathrm{Ti}_{4} \mathrm{MoSiB}_{2}$ and $\mathrm{Mo}_{5} \mathrm{SiB}_{2}$ compared to $\mathrm{Ti}_{5} \mathrm{SiB}_{2}$. Recently, we demonstrated that the preference for order or solid solution upon metal alloying in 212 MAB phases is dictated by for example the size difference between the alloying metal elements, ${ }^{58}$ also shown for alloying of 211 MAX phases. ${ }^{59}$ On the other hand, out-ofplane MAX phases, $o$-MAX, is possible when the atomic sizes of the alloying metals are similar while the difference in electronegativity between $\mathrm{M}^{\prime}$ and $\mathrm{A}$ is large. ${ }^{11}$

With these results in mind, we here aim to identify the attributes governing the preference for the formation of $o$-MAB or solid solution MAB by considering the electronegativity $\chi$ and atomic size $r$ of $\mathbf{M}^{\prime}$ and $\mathbf{M}^{\prime \prime}$, see Table S8 (ESI $\dagger$ ) for considered values. From the stability results in Fig. 3, it is found that out of the 910 compositions considered initially, only 157 are found to be thermodynamically stable. Out of these, 36 have the chemically ordered $o$-MAB as the preferred structure while 121 have the disorder solid solution as the favored distribution of $\mathbf{M}^{\prime}$ and $\mathbf{M}^{\prime \prime \prime}$. The information displayed in Fig. 3 thus only represent the chemical distribution of $\mathbf{M}^{\prime}$ and $\mathbf{M}^{\prime \prime}$ of the lowest energy, and thus do not explicitly show how close or far in energy the two different chemical distributions are, i.e., o-MAB vs. solid solution.

Fig. 4a shows the energy difference, $\Delta E=H_{o-\mathrm{MAB}}-$ $G_{\text {solid solution MAB }}$, between the chemically ordered $o$-MAB and the disordered solid solution MAB phase, as a function of the electronegativity difference of $\mathbf{M}^{\prime \prime}$ and $\mathbf{M}^{\prime}, \Delta \chi=\chi_{\mathrm{M}^{\prime \prime}}-\chi_{\mathrm{M}^{\prime}}$, for the 157 phases predicted stable in Fig. 3. $\Delta E<0$ represents the phases with chemical order (o-MAB) of the lowest energy and $\Delta E>0$ those phases which favor a disordered solid solution. In addition, experimentally reported quaternary MAB phases are 

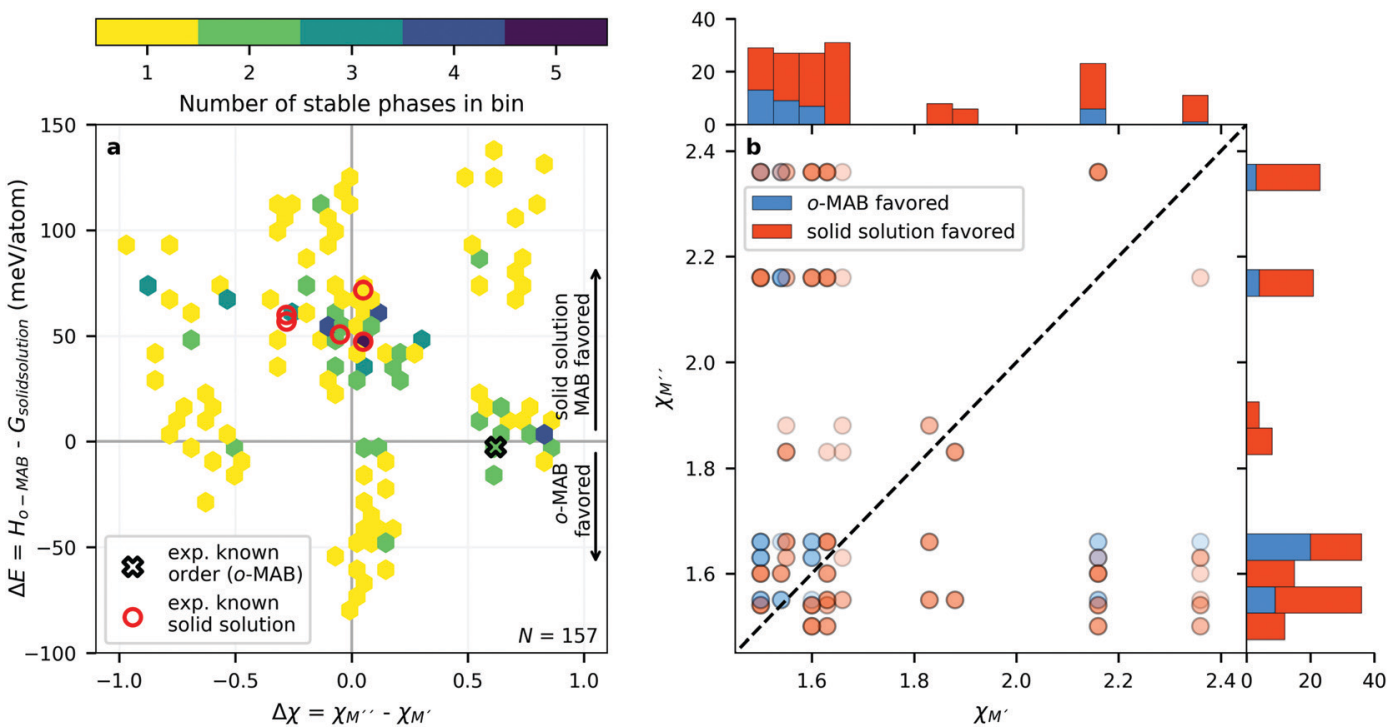

Fig. 4 (a) Hexbin plot showing the energy difference of chemical order $\left(\Delta H_{O-M A B}\right)$ and chemical disorder $\left(\Delta G_{\text {solid solution }}\right.$ at $\left.2000 \mathrm{~K}\right)$ as a function of electronegativity difference, $\Delta \chi$, of $\mathrm{M}^{\prime \prime}$ and $\mathrm{M}^{\prime}$ for phases identified as stable. The color of each hexagon represents the number of stable phases. The experimentally known o-MAB phase is indicated by a black cross and solid solution MAB phases by red circles. (b) Electronegativity $\chi$ of $\mathrm{M}^{\prime \prime}$ as a function of $\mathrm{M}^{\prime}$ for stable compositions, where the color of each data point represents if order (blue) or solid solution (red) is lowest in energy for a given composition. The dashed line represents $\chi_{\mathrm{M}^{\prime \prime}}=\chi_{\mathrm{M}^{\prime}}$. Histograms are given for each axis with a bin size of 0.05 .

marked. It is found that there is no clear correlation between $\Delta E$ and $\Delta \chi$, as indicated by the scattering data. Furthermore, instead of looking at $\Delta \chi$ we also choose to present the electronegativity of the individual metals, $\chi_{\mathrm{M}^{\prime}}$ and $\chi_{\mathrm{M}^{\prime \prime}}$, in Fig. $4 \mathrm{~b}$, together with the preferred chemical distribution of $\mathrm{M}^{\prime}$ and $\mathrm{M}^{\prime \prime}$ in blue (o-MAB) and red (solid solution MAB). Once again, we find no clear correlation between the individual electronegativity of $\mathrm{M}^{\prime}$ and $\mathrm{M}^{\prime \prime}$ and any specific preference for the phase being chemically ordered or disordered. Data including all 910 compositions are shown in Fig. S6 (ESI $\dagger$ ), which further support that electronegativity cannot be used to explain when $o-\mathrm{MAB}$ or solid solution MAB is to be expected.

In Fig. 5, we instead look at $\Delta E$ for the 157 stable phases as a function of the size difference of $\mathrm{M}^{\prime \prime}$ and $\mathrm{M}^{\prime}, \Delta r=r_{\mathrm{M}^{\prime \prime}}-r_{\mathrm{M}^{\prime}}$, where, once again, $\Delta E<0$ represents the phases with preferred chemical order $(o-\mathrm{MAB})$ and $\Delta E>0$ represents phases which
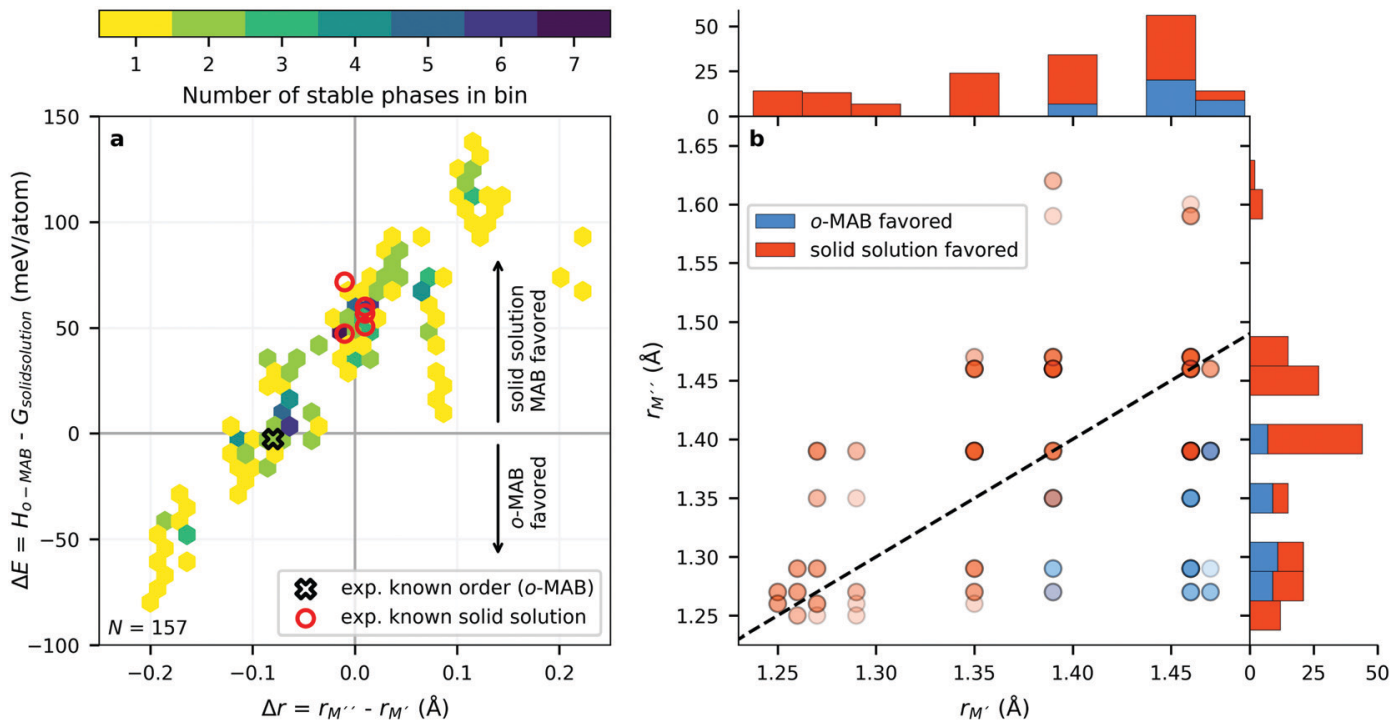

Fig. 5 (a) Hexbin plot showing the energy difference of chemical order $\left(\Delta H_{O-M A B}\right)$ and chemical disorder $\left(\Delta G_{\text {solid solution }}\right.$ at $\left.2000 \mathrm{~K}\right)$ as a function of the size difference, $\Delta r$, of $M^{\prime \prime}$ and $M^{\prime}$ for phases identified as stable. The color of each hexagon represents the number of stable phases. Experimentally known O-MAB phase is indicated by a black cross and solid solution MAB phases by red circles. (b) Atomic size $r$ of $\mathrm{M}^{\prime \prime}$ as a function of $\mathrm{M}^{\prime}$ for stable compositions where the color of each data point represents if order (blue) or solid solution (red) is lowest in energy for a given composition. The dashed line represents $r_{\mathrm{M}^{\prime \prime}}=r_{\mathrm{M}^{\prime}}$. Histograms are given for each axis with a bin size of $0.025 \AA$. 
favor a disordered solid solution. First to note is that similar results are found for all A-elements indicating that the impact on the choice of $\mathrm{A}$ is minimal and does not influence the energy difference between order and solid solution (see Fig. S7, ESI $\dagger$ ). From the data we find a correlation, where $\Delta E$ decreases/ increases upon decreasing/increasing the $\Delta r$ value. More specifically, data points with $\Delta E<0$, i.e., where the chemical order $(o-\mathrm{MAB})$ is energetically preferred, are only found for $\Delta r<0$ which means that the size of $\mathbf{M}^{\prime \prime}$ should be smaller than that of $\mathrm{M}^{\prime}$. In contrast, for $\Delta r \geq 0$ where $r_{\mathrm{M}^{\prime \prime}} \geq r_{\mathrm{M}^{\prime}}$ only disorder solid solution $\mathrm{MAB}$ phases are found as indicated by $\Delta E>0$. Experimentally known quaternary $\mathrm{T} 2$ phases are also marked in Fig. 5a where solid solutions (red circles) are all found in the region where the size of the metals is similar, $r_{\mathrm{M}^{\prime \prime}} \approx r_{\mathrm{M}^{\prime}}$ while $\mathrm{Ti}_{4} \mathrm{MoSiB}_{2} O$-MAB (black cross) is found at $\Delta r=-0.08$.

From the individual size of the metals, $r_{\mathrm{M}^{\prime}}$ and $r_{\mathrm{M}^{\prime \prime}}$, in Fig. $5 \mathrm{~b}$ we also find that stable $o$-MAB phases (blue) are comprised of $\mathrm{M}^{\prime \prime}$ with a size smaller than $1.40 \AA$ (corresponds to $\mathrm{M}^{\prime \prime}$ typically from Groups 6 to 9 ) and $\mathrm{M}^{\prime}$ with $r_{\mathrm{M}^{\prime}} \geq 1.38 \AA$ (corresponds to $\mathrm{M}^{\prime}$ typically from Group 4 or from Periods 5 and 6 combined with Groups 5 and 6). Data in favor of solid solution MAB (red) are more scattered and include a combination of metals of all sizes. An additional comparison including all 910 compositions is shown in Fig. S8 $(\mathrm{ESI} \dagger)$.

All of the five synthesized solid solution $\left(\mathrm{M}_{0.8}^{\prime} \mathrm{M}_{0.2}^{\prime \prime}\right)_{5} \mathrm{AB}_{2}$ phases have $\Delta E>0$, i.e., solid solutions are favored, and are comprised of metal combinations where both the size and electronegativity of $\mathbf{M}^{\prime}$ and $\mathbf{M}^{\prime \prime}$ are similar. This is consistent with the Hume-Rothery rules which state that a solid solution is expected when the alloying elements have a similar size and electronegativity. ${ }^{60}$ To explain why $\Delta E<0$, favoring chemically ordered $o-\mathrm{MAB}$, is only valid for $\Delta r<0$, we could argue that $\mathbf{M}^{\prime \prime}$ should be smaller than $\mathbf{M}^{\prime}$ because $\mathbf{M}^{\prime \prime}$ is constrained in a layer together with B. $\mathbf{M}^{\prime}$, on the other hand, forms a layer by itself where there is somewhat more space. By looking at the individual size of the metals in Fig. $5 \mathrm{~b}$ we find that both metals should be rather small, e.g., no large Sc or Y atoms are found among the stable $o$-MAB phases (see Fig. 3). The reason for this could be related to the structure, which cannot accommodate the metals if they are too large. For example, $\mathbf{M}^{\prime \prime}=\mathrm{Y}$ would result in an overall expansion of the structure which, in turn, would lead to increased bond lengths, decreased interaction strengths and thus reduced internal stability of the structure. Indications for such arguments are visualized from a structural point-of-view in Fig. S9 and S10 (ESI $\dagger$ ), where the large size of $\mathbf{M}^{\prime \prime}$ and $\mathbf{M}^{\prime}$ results in phases far from being stable and with large lattice parameters. All stable and ordered phases (o-MAB) display similar calculated lattice parameters, with $5.8 \AA<a<$ $6.2 \AA$ and $10.9 \AA<c<11.8 \AA$. This can be compared with all compositions with calculated lattice parameters in the range of $5.3 \AA<a<7.0 \AA$ and $9.5 \AA<c<14.4 \AA$.

To summarize the key results governing the formation of $o$ MAB or solid solution, we find indications for ordered $o$-MAB being the preferred structure over a solid solution when the size of $\mathbf{M}^{\prime}$ is larger than $\mathbf{M}^{\prime \prime}$ and where $\mathbf{M}^{\prime}$ should not be too large. No clear corresponding correlation could be identified when the solid solution $\left(\mathrm{M}_{0.8}^{\prime} \mathrm{M}_{0.2}^{\prime \prime}\right)_{5} \mathrm{AB}_{2}$ is the preferred structure. However, it should be noted that all of the five experimentally known solid solution MAB phases are comprised of metals of similar sizes.

To date, there have been many failed attempts to convert traditional ternary metal borides (MAB phases) into their 2D counterparts. $^{24,61,62}$ This contrasts to MXenes which are being successfully derived through complete etching of A from ternary metal carbides or nitrides (MAX phases). ${ }^{4,63}$ One reason for this may be the stronger interlayer bonding between metals and the A-layer in MAB phases as compared to MAX phases. Alloying can be used as an approach for modifying the interlayer interaction, which could facilitate the conversion from $3 \mathrm{D}$ into $2 \mathrm{D}$. This has been recently demonstrated for $\mathrm{Mo}_{4 / 3} \mathrm{Sc}_{2 / 3} \mathrm{AlB}_{2}$ and $\mathrm{Mo}_{4 / 3} \mathrm{Y}_{2 / 3} \mathrm{AlB}_{2}$ which was converted into $\mathrm{Mo}_{4 / 3} \mathrm{~B}_{2-x}$ boridene. ${ }^{28}$ Furthermore, in a most recent study, we synthesized $\mathrm{Ti}_{4} \mathrm{MoSiB}_{2}$, an $o$-MAB phase with proven outof-plane chemical order of $\mathrm{Ti}$ and Mo, from which we subsequently derived a new $2 \mathrm{D}$ material, $\mathrm{TiO}_{x} \mathrm{Cl}_{y}$, of high yield and in the form of delaminated sheets. ${ }^{37}$ The parent materials needed to realize these 2D materials were obtained through metal alloying of ternary MAB phases. This emphasizes that in our quest for finding novel $2 \mathrm{D}$ materials we must explore and enlarge the palette of materials from which they originate. In this work we demonstrate that there are numerous thermodynamically stable candidates not yet synthesized but promising for experimental realization.

\section{Conclusion}

In conclusion, we have performed a systematic theoretical study of the phase stability of quaternary T2 phases upon alloying between $\mathrm{M}^{\prime}$ and $\mathrm{M}^{\prime \prime}$ from Groups 3 to 9 (Sc, Y, Ti, Zr, $\mathrm{Hf}, \mathrm{V}, \mathrm{Nb}, \mathrm{Ta}, \mathrm{Cr}, \mathrm{Mo}, \mathrm{W}, \mathrm{Mn}, \mathrm{Fe}$, and $\mathrm{Co}$ ) for various $\mathrm{A}^{-}$ elements (Al, Si, P, Ga, and $\mathrm{Ge}$ ). We not only confirm all synthesized phases to date with chemical order (o-MAB) or disorder (solid solution) but also predict 35 stable $o$-MAB phases and 121 stable solid solutions. These hypothetical phases remain to be experimentally verified, and synthesis is encouraged. The preference for order or solid solution upon metal alloying in $\mathrm{T} 2$ phases is dictated mainly by the size difference between the alloying metal elements. Chemically ordered $o$-MAB $\left(M_{4}^{\prime} M^{\prime \prime} A_{2}\right)$ is energetically favored when $M^{\prime}$, next to the A layer, is larger than the metal $\mathbf{M}^{\prime \prime}$ in the $\mathbf{M}^{\prime \prime}-\mathrm{B}$ layer. Phases with similar sizes of $\mathbf{M}^{\prime}$ and $\mathbf{M}^{\prime \prime}$ or with $\mathbf{M}^{\prime}$ smaller than $\mathbf{M}^{\prime \prime}$ show a preference for the formation of disordered solid solution $\left(\mathrm{M}_{0.8}^{\prime} \mathrm{M}_{0.2}^{\prime \prime}\right)_{5} \mathrm{AB}_{2}$. This study demonstrates that alloying is a viable path towards novel elemental combinations, to extend the chemical space of T2 phases which, in turn, allows for potentially tuneable and advantageous properties. Furthermore, we expand the family of potential parent phases for the derivation of $2 \mathrm{D}$ materials from chemical exfoliation.

\section{Author contributions}

M. D. and J. R. initiated the study and wrote the manuscript. M. D. performed the ab initio calculations. 


\section{Conflicts of interest}

There are no conflicts to declare.

\section{Acknowledgements}

J. R. acknowledges the support from the Knut and Alice Wallenberg (KAW) Foundation for a Fellowship/Scholar Grant and Project funding (KAW 2020.0033), and from the Swedish Foundation for Strategic Research (SSF) for Project Funding (EM16-0004). The support from the Swedish Government Strategic Research Area in Materials Science on Functional Materials at Linköping University (Faculty Grant SFO-Mat-LiU No 2009 00971) is also acknowledged. The calculations were carried out using supercomputer resources provided by the Swedish National Infrastructure for Computing (SNIC) at the PDC Center for High Performance Computing partially funded by the Swedish Research Council through grant agreement no. 2018-05973.

\section{References}

1 W. Jeitschko, H. Nowotny and F. Benesovsky, Kohlenstoffhaltige ternäre Verbindungen (H-Phase), Monatsh. Chem., 1963, 94, 672-676.

$2 \mathrm{M}$. W. Barsoum, The $\mathrm{M}_{N+1} \mathrm{AX}_{N}$ phases: A new class of solids; Thermodynamically stable nanolaminates, Prog. Solid State Chem., 2000, 28, 201-281.

3 M. W. Barsoum, MAX Phases, Properties of Machinable Ternary Carbides and Nitrides. Wiley: New York, 2013.

4 M. Naguib, M. Kurtoglu, V. Presser, J. Lu, J. Niu, M. Heon, L. Hultman, Y. Gogotsi and M. W. Barsoum, Twodimensional nanocrystals produced by exfoliation of $\mathrm{Ti}_{3} \mathrm{AlC}_{2}$, Adv. Mater., 2011, 23, 4248-4253.

5 M. R. Lukatskaya, O. Mashtalir, C. E. Ren, Y. Dall'Agnese, P. Rozier, P. L. Taberna, M. Naguib, P. Simon, M. W. Barsoum and Y. Gogotsi, Cation Intercalation and High Volumetric Capacitance of Two-Dimensional Titanium Carbide, Science, 2013, 341, 1502-1505.

6 M. Ghidiu, M. R. Lukatskaya, M.-Q. Zhao, Y. Gogotsi and M. W. Barsoum, Conductive two-dimensional titanium carbide 'clay' with high volumetric capacitance, Nature, 2014, 516, 78-81.

7 F. Shahzad, M. Alhabeb, C. B. Hatter, B. Anasori, S. Man Hong, C. M. Koo and Y. Gogotsi, Electromagnetic interference shielding with 2D transition metal carbides (MXenes), Science, 2016, 353, 1137-1140.

8 B. Anasori, M. R. Lukatskaya and Y. Gogotsi, 2D metal carbides and nitrides (MXenes) for energy storage, Nat. Rev. Mater., 2017, 2, 16098.

9 B. Anasori, M. Dahlqvist, J. Halim, E. J. Moon, J. Lu, B. C. Hosler, E. N. Caspi, S. J. May, L. Hultman, P. Eklund, J. Rosén and M. W. Barsoum, Experimental and theoretical characterization of ordered MAX phases $\mathrm{Mo}_{2} \mathrm{TiAlC}_{2}$ and $\mathrm{Mo}_{2} \mathrm{Ti}_{2} \mathrm{AlC}_{3}$, J. Appl. Phys., 2015, 118, 094304.
10 Q. Tao, M. Dahlqvist, J. Lu, S. Kota, R. Meshkian, J. Halim, J. Palisaitis, L. Hultman, M. W. Barsoum, P. O. Å. Persson and J. Rosen, Two-dimensional $\mathrm{Mo}_{1.33} \mathrm{C}$ MXene with divacancy ordering prepared from parent 3D laminate with inplane chemical ordering, Nat. Commun., 2017, 8, 14949.

11 M. Dahlqvist and J. Rosen, Predictive theoretical screening of phase stability for chemical order and disorder in quaternary 312 and 413 MAX phases, Nanoscale, 2020, 12, 785-794.

12 B. Anasori, Y. Xie, M. Beidaghi, J. Lu, B. C. Hosler, L. Hultman, P. R. C. Kent, Y. Gogotsi and M. W. Barsoum, Two-dimensional, ordered, double transition metals carbides (MXenes), ACS Nano, 2015, 9, 9507-9516.

13 R. Meshkian, Q. Tao, M. Dahlqvist, J. Lu, L. Hultman and J. Rosen, Theoretical stability and materials synthesis of a chemically ordered MAX phase, $\mathrm{Mo}_{2} \mathrm{ScAlC}_{2}$, and its twodimensional derivate $\mathrm{Mo}_{2} \mathrm{ScC}_{2}$ MXene, Acta Mater., 2017, 125, 476-480.

14 I. Persson, A. e. Ghazaly, Q. Tao, J. Halim, S. Kota, V. Darakchieva, J. Palisaitis, M. W. Barsoum, J. Rosen and P. O. A. Persson, Tailoring Structure, Composition, and Energy Storage Properties of MXenes from Selective Etching of In-Plane, Chemically Ordered MAX Phases, Small, 2018, 14, 1703676.

15 G. Deysher, C. E. Shuck, K. Hantanasirisakul, N. C. Frey, A. C. Foucher, K. Maleski, A. Sarycheva, V. B. Shenoy, E. A. Stach, B. Anasori and Y. Gogotsi, Synthesis of $\mathrm{Mo}_{4} \mathrm{VAlC}_{4}$ MAX Phase and Two-Dimensional $\mathrm{Mo}_{4} \mathrm{VC}_{4}$ MXene with Five Atomic Layers of Transition Metals, ACS Nano, 2020, 14, 204-217.

16 H. J. Becher, K. Krogmann and E. Peisker, Über das ternäre Borid $\mathrm{Mn}_{2} \mathrm{AlB}_{2}$, Zeitschrift für anorganische und allgemeine Chemie, 1966, 344, 140-147.

17 M. Ade and H. Hillebrecht, Ternary Borides $\mathrm{Cr}_{2} \mathrm{AlB}_{2}, \mathrm{Cr}_{3} \mathrm{AlB}_{4}$, and $\mathrm{Cr}_{4} \mathrm{AlB}_{6}$ : the First Members of the Series $\left(\mathrm{CrB}_{2}\right)_{n} \mathrm{CrAl}$ with $n$ $=1,2,3$ and a Unifying Concept for Ternary Borides as MABPhases, Inorg. Chem., 2015, 54, 6122-6135.

18 D. Potashnikov, E. N. Caspi, A. Pesach, S. Kota, M. Sokol, L. A. Hanner, M. W. Barsoum, H. A. Evans, A. Eyal, A. Keren and O. Rivin, Magnetic properties of $\left(\mathrm{Fe}_{1-x} \mathrm{Mn}_{x}\right)_{2} \mathrm{AlB}_{2}$ and the impact of substitution on the magnetocaloric effect, Phys. Rev. Mater., 2020, 4, 084404.

19 H. Zhang, F.-Z. Dai, H. Xiang, Z. Zhang and Y. Zhou, Crystal structure of $\mathrm{Cr}_{4} \mathrm{AlB}_{4}$ : a new MAB phase compound discovered in Cr-Al-B system, J. Mater. Sci. Technol., 2018, 35, 530-534.

20 N. Miao, J. Wang, Y. Gong, J. Wu, H. Niu, S. Wang, K. Li, A. R. Oganov, T. Tada and H. Hosono, Computational prediction of boron-based MAX phases and MXene derivatives, Chem. Mater., 2020, 32, 6947-6957.

21 M. M. Ali, M. A. Hadi, I. Ahmed, A. F. M. Y. Haider and A. K. M. A. Islam, Physical properties of a novel boron-based ternary compound $\mathrm{Ti}_{2} \mathrm{InB}_{2}$, Mater. Today Commun., 2020, 25, 101600.

22 H. Nowotny, E. Dimakopoulou and H. Kudielka, Untersuchungen in den Dreistoffsystemen: Molybdän-Silizium-Bor, 
Wolfram-Silizium-Bor und in dem System: $\mathrm{VSi}_{2}-\mathrm{TaSi}_{2}$, Monatsh. Chem., 1957, 88, 180-192.

23 L. T. Alameda, C. F. Holder, J. L. Fenton and R. E. Schaak, Partial Etching of Al from MoAlB Single Crystals To Expose Catalytically Active Basal Planes for the Hydrogen Evolution Reaction, Chem. Mater., 2017, 29, 8953-8957.

24 L. T. Alameda, R. W. Lord, J. A. Barr, P. Moradifar, Z. P. Metzger, B. C. Steimle, C. F. Holder, N. Alem, S. B. Sinnott and R. E. Schaak, Multi-Step Topochemical Pathway to Metastable $\mathrm{Mo}_{2} \mathrm{AlB}_{2}$ and Related TwoDimensional Nanosheet Heterostructures, J. Am. Chem. Soc., 2019, 141, 10852-10861.

25 K. Kim, C. Chen, D. Nishio-Hamane, M. Okubo and A. Yamada, Topochemical synthesis of phase-pure $\mathrm{Mo}_{2} \mathrm{AlB}_{2}$ through staging mechanism, Chem. Commun., 2019, 55, 9295-9298.

26 M. Dahlqvist, Q. Tao, J. Zhou, J. Palisaitis, P. O. Å. Persson and J. Rosen, Theoretical Prediction and Synthesis of a Family of Atomic Laminate Metal Borides with In-Plane Chemical Ordering, J. Am. Chem. Soc., 2020, 142, 18583-18591.

27 B. Ahmed, A. E. Ghazaly and J. Rosen, i-MXenes for Energy Storage and Catalysis, Adv. Funct. Mater., 2020, 30, 2000894.

28 J. Zhou, J. Palisaitis, J. Halim, M. Dahlqvist, Q. Tao, I. Persson, L. Hultman, P. O. Å. Persson and J. Rosen, Boridene: Two-dimensional Mo4/3B2 $\_x$ with ordered metal vacancies obtained by chemical exfoliation, Science, 2021, 373, 801-805.

29 B. Aronsson and I. Engström, X-Ray Investigations on M-SiB Systems ( $\mathrm{M}=\mathrm{Mn}, \mathrm{Fe}, \mathrm{Co})$. II. Some Features of the Fe-Si-B and Mn-Si-B Systems, Acta Chem. Scand., Ser. A, 1960, 14, 1403-1413.

30 M. K. Meyer and M. Akinc, Oxidation Behavior of BoronModified $\mathrm{Mo}_{5} \mathrm{Si}_{3}$ at 800-1300 ${ }^{\circ} \mathrm{C}, \mathrm{J}$. Am. Ceram. Soc., 1996, 79, 938-944.

31 C. J. Rawn, J. H. Schneibel, C. M. Hoffmann and C. R. Hubbard, The crystal structure and thermal expansion of $\mathrm{Mo}_{5} \mathrm{SiB}_{2}$, Intermetallics, 2001, 9, 209-216.

32 A. Brauner, C. A. Nunes, A. D. Bortolozo, G. Rodrigues and A. J. S. Machado, Superconductivity in the new $\mathrm{Nb}_{5} \mathrm{Si}_{3-x} \mathrm{~B}_{x}$ phase, Solid State Commun., 2009, 149, 467-470.

33 M. A. McGuire and D. S. Parker, Superconductivity at $9 \mathrm{~K}$ in $\mathrm{Mo}_{5} \mathrm{~PB}_{2}$ with evidence for multiple gaps, Phys. Rev. B, 2016, 93, 064507.

34 D. Hedlund, J. Cedervall, A. Edström, M. Werwiński, S. Kontos, O. Eriksson, J. Rusz, P. Svedlindh, M. Sahlberg and K. Gunnarsson, Magnetic properties of the $\mathrm{Fe}_{5} \mathrm{SiB}_{2}$ $\mathrm{Fe}_{5} \mathrm{~PB}_{2}$ system, Phys. Rev. B, 2017, 96, 094433.

35 J. Cedervall, E. Nonnet, D. Hedlund, L. Häggström, T. Ericsson, M. Werwiński, A. Edström, J. Rusz, P. Svedlindh, K. Gunnarsson and M. Sahlberg, Influence of Cobalt Substitution on the Magnetic Properties of $\mathrm{Fe}_{5} \mathrm{~PB}_{2}$, Inorg. Chem., 2018, 57, 777-784.

36 R. Hirian, O. Isnard, V. Pop and D. Benea, Investigations on the magnetic properties of the $\mathrm{Fe}_{5-\mathrm{x}} \mathrm{Co}_{\mathrm{x}} \mathrm{SiB}_{2}$ alloys by experimental and band structure calculation methods, J. Magn. Magn. Mater., 2020, 505, 166748.
37 M. Dahlqvist, J. Zhou, I. Persson, B. Ahmed, J. Lu, J. Halim, Q. Tao, J. Palisaitis, J. Thörnberg, P. Helmer, L. Hultman, P. O. Å. Persson and J. Rosen, Out-Of-Plane Ordered Laminate Borides and Their 2D Ti-Based Derivative from Chemical Exfoliation, Adv. Mater., 2021, 33, 2008361.

38 P. Helmer, H. Lind, M. Dahlqvist and J. Rosen, Investigation of out-of-plane ordered $\mathrm{Ti}_{4} \mathrm{MoSiB}_{2}$ from first principles, J. Phys.: Condens. Matter, 2022, DOI: 10.1088/1361-648X/ ac51fe.

39 G. Kresse and J. Hafner, Ab initio molecular dynamics for liquid metals, Phys. Rev. B: Condens. Matter Mater. Phys., 1993, 47, 558-561.

40 G. Kresse and J. Furthmüller, Efficiency of ab-initio total energy calculations for metals and semiconductors using a plane-wave basis set, Comput. Mater. Sci., 1996, 6, 15-50.

41 G. Kresse and J. Furthmüller, Efficient iterative schemes for $a b$ initio total-energy calculations using a plane-wave basis set, Phys. Rev. B: Condens. Matter Mater. Phys., 1996, 54, 11169-11186.

42 P. E. Blöchl, Projector augmented-wave method, Phys. Rev. B: Condens. Matter Mater. Phys., 1994, 50, 17953-17979.

43 G. Kresse and D. Joubert, From ultrasoft pseudopotentials to the projector augmented-wave method, Phys. Rev. B: Condens. Matter Mater. Phys., 1999, 59, 1758-1775.

44 J. P. Perdew, K. Burke and M. Ernzerhof, Generalized gradient approximation made simple, Phys. Rev. Lett., 1996, 77, 3865-3868.

45 H. J. Monkhorst and J. D. Pack, Special points for Brillouinzone integrations, Phys. Rev. B: Solid State, 1976, 13, 5188-5192.

46 A. Zunger, S. H. Wei, L. G. Ferreira and J. E. Bernard, Special quasirandom structures, Phys. Rev. Lett., 1990, 65, 353-356.

47 M. Dahlqvist, B. Alling, I. A. Abrikosov and J. Rosén, Phase stability of $\mathrm{Ti}_{2} \mathrm{AlC}$ upon oxygen incorporation: A firstprinciples investigation, Phys. Rev. B: Condens. Matter Mater. Phys., 2010, 81, 024111.

48 M. Dahlqvist, B. Alling and J. Rosén, Stability trends of MAX phases from first principles, Phys. Rev. B: Condens. Matter Mater. Phys., 2010, 81, 220102.

49 P. Eklund, M. Dahlqvist, O. Tengstrand, L. Hultman, J. Lu, N. Nedfors, U. Jansson and J. Rosén, Discovery of the ternary nanolaminated compound $\mathrm{Nb}_{2} \mathrm{GeC}$ by a systematic theoretical-experimental approach, Phys. Rev. Lett., 2012, 109, 035502.

50 A. S. Ingason, A. Mockute, M. Dahlqvist, F. Magnus, S. Olafsson, U. B. Arnalds, B. Alling, I. A. Abrikosov, B. Hjörvarsson, P. O. Å. Persson and J. Rosen, Magnetic self-organized atomic laminate from first principles and thin film synthesis, Phys. Rev. Lett., 2013, 110, 195502.

51 A. S. Ingason, A. Petruhins, M. Dahlqvist, F. Magnus, A. Mockute, B. Alling, L. Hultman, I. A. Abrikosov, P. O. A. Persson and J. Rosen, A nanolaminated magnetic phase: Mn2GaC, Mater. Res. Lett., 2014, 2, 89-93.

52 A. Mockute, M. Dahlqvist, J. Emmerlich, L. Hultman, J. M. Schneider, P. O. Å. Persson and J. Rosen, Synthesis and $a b$ initio calculations of nanolaminated $(\mathrm{Cr}, \mathrm{Mn})_{2} \mathrm{AlC}$ 
compounds, Phys. Rev. B: Condens. Matter Mater. Phys., 2013, 87, 094113.

53 A. Mockute, P. O. Å. Persson, F. Magnus, A. S. Ingason, S. Olafsson, L. Hultman and J. Rosen, Synthesis and characterization of arc deposited magnetic (Cr,Mn) $)_{2}$ AlC MAX phase films, Phys. Status Solidi RRL, 2014, 8, 420-423.

54 A. Thore, M. Dahlqvist, B. Alling and J. Rosén, Temperature dependent phase stability of nanolaminated ternaries from first-principles calculations, Comput. Mater. Sci., 2014, 91, 251-257.

55 K. Momma and F. Izumi, VESTA 3 for three-dimensional visualization of crystal, volumetric and morphology data, J. Appl. Crystallogr., 2011, 44, 1272-1276.

56 M. A. McGuire and D. S. Parker, Magnetic and structural properties of ferromagnetic Fe5PB2 and Fe5SiB2 and effects of Co and Mn substitutions, J. Appl. Phys., 2015, 118, 163903.

57 D. M. de Almeida, C. Bormio-Nunes, C. A. Nunes, A. A. Coelho and G. C. Coelho, Magnetic characterization of $\mathrm{Mn}_{5} \mathrm{SiB}_{2}$ and $\mathrm{Mn}_{5} \mathrm{Si}_{3}$ phases, J. Magn. Magn. Mater., 2009, 321, 2578-2581.
58 M. Dahlqvist and J. Rosen, Predictions of Attainable Compositions of Layered Quaternary $i$-MAB Phases and solid solution MAB phases, Nanoscale, 2021, 13, 18311.

59 M. Dahlqvist, A. Petruhins, J. Lu, L. Hultman and J. Rosen, Origin of Chemically Ordered Atomic Laminates (i-MAX): Expanding the Elemental Space by a Theoretical/Experimental Approach, ACS Nano, 2018, 12, 7761-7770.

60 W. Hume-Rothery; R. E. Smallman and C. W. Haworth, The structure of metals and alloys, The Institute of Metals, London, 1969.

61 L. T. Alameda, P. Moradifar, Z. P. Metzger, N. Alem and R. E. Schaak, Topochemical Deintercalation of Al from MoAlB: Stepwise Etching Pathway, Layered Intergrowth Structures, and Two-Dimensional MBene, J. Am. Chem. Soc., 2018, 140, 8833-8840.

62 J. Wang, T.-N. Ye, Y. Gong, J. Wu, N. Miao, T. Tada and $\mathrm{H}$. Hosono, Discovery of hexagonal ternary phase $\mathrm{Ti}_{2} \mathrm{InB}_{2}$ and its evolution to layered boride TiB, Nat. Commun., 2019, 10, 2284.

63 A. VahidMohammadi, J. Rosen and Y. Gogotsi, The world of two-dimensional carbides and nitrides (MXenes), Science, 2021, 372, eabf1581. 